\title{
TRUST AND SATISFACTION AS MEDIATORS OF PREMIUM PRICES
}

\author{
Arjun Chaudhuri, Fairfield University, U.S.A. \\ Mark Ligas, Fairfield University, U.S.A.
}

\begin{abstract}
We hypothesize that store trust will mediate the effect of merchandise value on shoppers' willingness to pay a higher price (WTPHP) but store satisfaction will not. WTPHP represents the surplus that arises from merchandise value which itself is derived from notions of perceived quality and actual price paid. When perceived quality is considered to be greater than the actual price paid, a surplus (merchandise value) is generated in the consumer's mind and results in WTPHP as long as the surplus exists (Monroe 2003). Although prior research (Chaudhuri and Ligas 2009) has found no direct linkage between these variables, it is feasible that such a relationship does exist and is mediated by other constructs such as store trust. We propose that value that is considered to be a good deal (consistent in terms of quality and price) leads to WTPHP indirectly via perceived trust but not via satisfaction. Merchandise value accounts for the "credibility" of the quality-price tradeoff, and trust is a logical outcome of a credible exchange (Moorman, Deshpandé and Zaltman 1993). Hence, we chose trust as the appropriate evaluation instead of satisfaction, etc. We expect that greater perceived value will indeed lead to greater satisfaction but that satisfaction will not lead to a willingness to pay a higher price. This is because satisfaction, unlike trust, is not necessarily indicative of a willingness to sacrifice resources to maintain a valued relationship. Trust indicates an alignment of mutually beneficial goals, and it is a stronger motivational state than satisfaction (Johnson and Selnes 2004).
\end{abstract}

We collected data from two retail establishments in northeastern U.S.A. Store A was a "traditional" grocery store while Store B was a "specialty" grocer, due to the limited amount of higher-priced and higher-quality items in the store. These stores were chosen to represent two different types of merchandise value (Grewal, Monroe and Krishnan 1998). One hundred and fifty questionnaires were collected from each store $(\mathrm{N}=300)$. We further developed and/or modified measures for our constructs of interest largely from items utilized in prior marketing research studies. All items for each construct were measured on 7-point scales, where 1= "completely disagree" and 7= "completely agree."

We conducted formal tests of mediation using regression analysis as per the four steps recommended by Baron and Kenny (1986). We found in the first step that the effect of perceived value on WTPHP was positive and significant $(\beta=.284 ; \mathrm{p}<$ $.01)$. In the second step, we found that the effect of perceived value on trust (mediator) was positive and significant $(\beta=.511$; $p<.01)$. In the third step, we found that the effect of trust (mediator) on WTPHP was positive and significant $(\beta=.395 ; p<$ .01 ). In the fourth step, we once again examined the effect of perceived value on WTPHP but this time we introduced trust into the equation as well. We found that when trust was in the equation, the effect of perceived value on WTPHP diminished in effect $(\beta=.117 ; p>.05)$ and became non-significant. Forty five percent of the variance in WTPHP was explained. We also tested satisfaction to see if it was a better mediator on perceived value leading to WTPHP than trust. When we regressed WTPHP on satisfaction we found that satisfaction (mediator) was significantly related to WTPHP $(\beta=.261 ; p<.01)$. We also found that perceived value was significantly related to satisfaction $(\beta=.557 ; p<.01)$. However, when both perceived value and satisfaction were in the model with WTPHP as the dependent variable, only the effect of perceived value was significant $(\beta=.211 ; p<.01)$. The effect of satisfaction reduced in size and became non-significant $(\beta=.132 ; p>.05)$. Thus, trust mediated the effect of perceived value on WTPHP but satisfaction did not. We also tested the effect of quadratic and cubic forms of satisfaction and found no evidence that any of these forms mediated the effect of perceived value on WTPHP.

The importance of understanding mediating influences should not be understated for practical purposes of managerial success. Evidence of a mediator in any relationship could be very helpful in potential cost effectiveness. For example, if managers know that trust mediates the effect of value on commitment, then they can take steps to find more cost effective means of producing trust since that is the actual and direct source of higher prices leading to profitable marketing outcomes. Managers could experiment with other sources of trust such as better service, advertising etc. and consider the effect of these alternatives to merchandise value. Obviously, any alternative strategies should only be implemented after careful understanding of what effect the removal of "good deals" or merchandise value would have on sales and other variables as well. For instance, the "lack" of a good deal may concurrently have deleterious effects that negate the positive effect of alternative strategies.

References Available Upon Request 